\title{
LEGADO DE CARMEN RIVERA DE ALVARADO A LA PROFESION DE TRABAJO SOCIAL EN PUERTO RICO
}

\section{Raquel M. Seda Rodríguez ${ }^{2}$}

\author{
Alabanzas para los estudiantes de \\ trabajo social que participaron en \\ la reciente huelga universitaria, \\ emulando las gestas de Carmen Rivera \\ de Alvarado.
}

Y la llamaron Carmen, cuando abrió sus ojos por primera vez a este plano terrenal. Luego, fue Cambur para su familia, Doña Carmen y Dra. Alvarado para quienes tuvimos el privilegio de nutrirnos con su sabiduría. Nació esta excepcional mujer, el 30 de junio de 1910 en la ruralía de nuestro País, en el Barrio Pugnado Afuera de Vega Baja. Hija de Don Facundo Rivera Natal y Doña Carmen Landrón y Landrón. Artífice éstos de una familia unida por el amor, la solidaridad y la justicia.

Los primeros años de Doña Carmen transcurrieron en el mismo barrio en que nació, en la casa grande familiar, junto a sus padres, hermanos y hermanas y otros familiares. Siempre amó el campo y a su gente humilde.

${ }^{1}$ Conferencia presentada en la Asamblea Anual del Colegio de Trabajadores Sociales de Puerto Rico, celebrada del 11 al 13 de noviembre de 2010, en el Hotel El Conquistador en Fajardo, Puerto Rico.

${ }^{2}$ Catedratica Jubilada Escuela Graduada de Trabajo Social, Universidad de Puerto Rico 
$\overline{\text { A sus dieciséis años y honrando su nombre, que está asociado a un }}$ jardín y a la poesía; nos regaló en un poema, lo que habría de ser la esencia de su vida.

Florida toda yo por los caminos

Como el roble rosado en primavera

Vagaré bajo el ala de las nubes

Sobre el barro sagrado de la tierra...

Florida toda yo. De margaritas,

De rosas y clavel las manos llenas

Un pensamiento frente

Y dentro el corazón, una azucena...

Sin mochila ni alforja a las espaldas

En donde almacenar pan o monedas

Florida toda yo, marcharé sola

Por las veredas...

A mi paso los campos una alfombra

Extenderán de suave y fresca yerba

Un lecho familiar me dará el campo

Un asiento solicito, las piedras,

$\mathrm{Y}$ cuando las espinas con encono

Cruel los pies me hieran

La fuente dará un bálsamo a mi herida

Y el ruiseñor mitigará mis penas
Con su voz. Y mi voz alzaré entonces

Al compás de sus cantos, un poema.

Florida toda yo, Incienso, aroma

De sándalo y de nardo mil esencias

Por los largos caminos de la tierra...

Y cuando de las gentes a mi lleguen

Las crueldades acerbas

Esgrimiré por aroma el pensamiento

Y de mi corazón una azucena

Los lanzaré a la faz, como un perfume

En el ritmo sonoro de un poema...

Y seguiré mi ruta

Toda florida yo por las veredas...

(Rivera, 1986, p. 17)

Esa sensibilidad hecha mujer fue reconocida como la peta de su clase en la Escuela Superior Central de Santurce, donde hizo sus estudios secundarios, obteniendo honores académicos. Para esta época, había perdido la visión en un ojo debido a un accidente mientras jugaba con una primita. Nunca tuvo resentimiento hacia ella, quien le había caudado esa seria lesión.

Doña Carmen obtuvo su diploma de la Escuela Normal de la Universidad de Puerto Rico en el 1930, recibiendo el Premio Carlota Metienzo, que se otorgaba al estudiante más distinguido y de más alto índice académico. En ese mismo año se inicio como trabajadora social, siendo una de las primeras veintiocho trabajadoras sociales en Puerto Rico.

VOCES DESDE EL TRABAJO SOCIAL

NÚM.1 
En el 1931 unió su vida a Don Julián Antonio Alvarado, nacido en el Barrio Botijas de Orocovis. Hasta la hora de su muerte, compartió con él un hogar noble y generoso, donde cabían todos y "sobraba espacio" para compartir Universitario, que circuitó de 1946 a 1947 y que contribuyó al clima de protesta estudiantil que culminó en la huelga de 1943. Nos dice el autor: "Este proyectos era apoyado por la Doctora Carmen Rivera de Alvarado, quien permitía que los estudiantes se reunieran de noche en lo que es hoy el Decanato de Estudiantes para laborar en el mismo" (Coló, 2009, p. 21). Y sobre esa huelga histórica de 1948, nos señala, quien se consideraba su discípulo y uno de nuestros más grandes patriotas, recientemente fallecido, el Lcdo. Juan Mari Brás:

Fue por eso que los universitarios de 1947 la escogimos para izar el pabellón nacional en la Torre en saludo al Maestro Albizu Campos el día de su llegada de la cárcel y el destierro. Aquel acto patriótico fue la causa inmediata de que Doña Carmen se convirtiera en la primera victima de la represión benitista en la administración universitaria. El rector eliminó la Junta de Servicios al Estudiante, convirtiéndola en decanato como pretexto APRA destituir a la doctora Alvarado del cargo (Rivera, 1986, p. 10).

Esa represión se repitió en innumerables ocasiones en su vida adulta. Fue víctima de la marginación y el discrimen aún de parte de colegas profesionales. Resistió con valentía y firmeza, tomándose más fuerte cada día.

En el 1944 había terminado una maestría en trabajo social en la Universidad de Washington, en St. Louis, Missouri. En la Universidad de Pennsylvania, en la ciudad de Philadelphia, se recibió de Doctora de Trabajo Social en el 1955. Estos grados académicos los obtuvo mientras ejercía como profesora en la Escuela Graduada de Trabajo Social de la Universidad de Puerto Rico, donde laboró por espacio de treinta años, de 1942 a 1972. No se limitó a su labor en dicha Escuela, sino que se proyectó a la Facultad de Ciencias Sociales. Su figura trascendió esa facultad, siendo miembro destacado del Senado Académico y de la Asociación Puertorriqueña de Profesores Universitarios, Su excelente labor universitaria fue reconocida por la Facultad de Ciencias sociales, quien solicitó a la administración de la Universidad de Puerto Rico, le concediera el rango de Profesora Emeritus. La Universidad se honró a si misma otorgándole ese titulo en la colación de grados del 1973. Doña Carmen no asistió a la ceremonia. Justificó su ausencia con la integridad, verticalidad y firmeza que la caracterizaban:

No asistí al acto de entrega de distinciones honoríficas para evitar que mi presencia pudiese interpretarse en forma alguna como expresión de solidaridad con la administración universitaria. Mi posición en la Universidad nunca ha sido la del intelectual neutral y aséptico. Siempre he estado comprometida con la Universidad en lo que considero su función esencia en la sociedad, que para mi es la formación de hombres y mujeres libres de espíritu, de pensamiento y de voluntad, ya que entiendo que la búsqueda de la verdad solo puede ser realizada por los que son verdaderamente libres. De otro modo, solo se logra el fenómeno tan común en las llamadas sociedades desarrolladas de una ciencia y una tecnología al servicio de la destrucción, la opresión, la explotación y el exterminio de gentes indefensas (Rivera, 1986, p. 143).

La labor profesional de Doña Carmen trascendió los límites nacionales, haciendo contribuciones excepcionales en eventos celebrados en Cuba, en México y Venezuela. En el 1972 fue nombrada Profesora Visitante Distinguida en la Escuela Graduada de Trabajo Social del Colegio Hunter en la ciudad de Nueva York. En dicha ciudad participó en el comité que presentó el caso colonial de Puerto Rico ante las Naciones Unidas. Fue invitada de honor del Departamento de Estudios Puertorriqueños del Colegio Lehman así como por el City College en la misma ciudad. En todos los periodos en que vivió en los Estados Unidos de Norteamérica, trabajó 
con los sectores más progresistas, por los derechos de los(as) puertorriqueños(as) sometidos al discrimen en dicho país.

Esta mujer, a quien recordamos hoy, tuvo un papel destacado en la lucha por darle a la mujer puertorriqueña una participación activa en los afanes de su pueblo, por romper las barreras del prejuicio que destinan a ésta al círculo limitado de las faenas domésticas y obstaculizan su aportación a los movimientos sociales.

Dentro de su cargado calendario, Doña Carmen siempre encontró tiempo para realizar trabajo voluntario. $\mathrm{Su}$ presencia fue notable en los campos de los derechos civiles, retardación mental, prevención y tratamiento del cáncer, salud mental, bienestar de la familia y delincuencia juvenil.

Nuestra Maestra, combinó siempre su responsabilidad profesional con una consagración total a la lucha por la independencia de Puerto Rico. Fue fundadora del Partido Independentista Puertorriqueño. Fue la más destacada de las mujeres fundadoras de ese partido y ocupó los más altos cargos en su estructura. Fue miembro fundador del Movimiento Proindependencia. En todo el proceso de forja de este movimiento, desde la concepción hasta su organización y desarrollo, Doña Carmen aportó ideas y acciones de extraordinaria utilidad que permitieron crecer a ese colectivo hasta convertirse en el Partido Socialista Puertorriqueño, en el que militó hasta la hora de su muerte, el 23 de julio de 1973.

¿Y cómo podía ella conjugar tan magistralmente su patriotismo y la conciencia social, que lo plasmó en la fundación de las dos organizaciones vanguardistas del trabajo social en Puerto Rico: Acción Social Puertorriqueña y la Asociación Nacional de Trabajadores Sociales de Puerto Rico? ¿Cómo es posible esta conjugación en una profesión, en que se intenta educarnos desde los enfoques mas conservadores, orientándonos a ser neutrales para que de esa manera podamos ser entes objetivos y no subjetivos en nuestra práctica profesional?

Permítanme un breve paréntesis para hacer un comentario sobre los conceptos neutralidad, subjetividad y objetividad. La neutralidad se debate desde diferentes perspectivas. Hay quienes defienden su existencia, quienes la caracterizan como un mito y quienes no creen en su existencia. Yo sostengo que es un vocablo que debemos eliminar de nuestro lenguaje profesional, por haber sido sumamente nocivo a nuestro desarrollo profesional y a nuestra contribución a un adelanto significativo del país en que vivimos y ejercemos como trabajadores(as) sociales. La llamada neutralidad intenta arrebatarnos nuestra facultad para pensar, sentir y actuar de acuerdo a nuestros principios éticos y el compromiso con la igualdad humana y la justicia social. Nos ha hecho parecer impotentes, faltos de seguridad, firmeza y valentía.

Los conceptos que si debemos trabajar intensamente son los de la subjetividad y la objetividad. Los seres humanos somos entes subjetivos. En nuestros procesos de socialización, internalizados marcos referenciales, que utilizamos para observar, estudiar, interpretar y actuar sobre la situación con que nos estemos confrontando. Es una responsabilidad profesional y personal, enfrentarnos a nuestra subjetividad y trabajar con ella. Esa tarea debe darse simultáneamente con el desarrollo de la objetividad, que si es necesaria en nuestra ejecutoria profesional. Tenemos la capacidad para ser objetivos(as) dentro de nuestra subjetividad. Esto se logra mediante procesos educativos liberadores, voluntad y disciplina. Sí a la objetividad, No a la neutralidad...!

La contestación a las interrogantes señaladas, antes del paréntesis, nos la ofrece Doña Carmen en su visión del trabajo social y la conjugación de éste y la lucha por la liberación nacional, que es: 
La de una disciplina personal que se comparte con los miembros de un grupo con metas y propósitos afines y que responde a unos conocimientos, pero más que nada, a una vocación que he dado en llamar "vocación de libertad", porque va dirigida tanto a la libertad integral de las persona, grupos o comunidades con quienes se trabaja, como a la del propio trabajador social; ya que solamente los que son libres pueden liberar a otros. A una ética, porque está basada en unos valores que no tienen que responder necesariamente a los valores de la sociedad de que forma parte el trabajador social. Este es un punto cuya importancia y cuya dificultad quiero recatar, ya que la mayor parte de las veces actuamos respondiendo más a los valores de nuestros patronos, las clases dominantes, que a los valores de nuestra propia profesión (Rivera, 1986, p. 146).

En su escrito Trabajo Social: Vocación de Libertad, nos dice: "La libertad y el trabajo social se afirman, pues, sobre el mismo fundamento: el amor y el respeto a los demás” (Rivera, 1986, p. 99)

\section{Y continúa:}

La función del trabajo social no se basa en el ejercicio del poder personal de un individuo sobre otro para el logro de metas fijadas en un plan prescrito por el trabajador social, sino en el reconocimiento del derecho del otro a ejercer la autodeterminación... porque el ejercicio de la autodeterminación es libertad y la libertad es una de las necesidades básicas del hombre, la que ha de ayudarle a encontrar la dirección y la razón de su existencia. (Rivera, 1986, p. 100).

Entendía ella que el coloniaje al que ha estado sometido el pueblo de Puerto Rico a través de su historia debe ser entendido y atendido con urgencia por nuestra clase profesional. Y nos pregunta directamente:

¿Cómo puede ser agente de cambio en una sociedad colonial, un profesional que ni siquiera se percata de que él también es un COLONIZADO? Porque el colonialismo no es únicamente un sistema político. Es además, un fenómeno económico, social, cultural y espiritual y particularmente psicológico que reclama la atención de todo trabajador social. Si es que en verdad nuestra profesión se preocupa más allá del nivel teórico, en el impacto que las estructuras, las instituciones y los fenómenos sociales tienen sobre las vidas de los seres humanos. Igualmente puede decirse respecto del neocolonialismo, del imperialismo, del racismo $y$ de todo fenómeno humano basado en el discrimen y en la opresión de los más en beneficio de pequeños grupos de privilegiados, donde quiera que éste se manifieste. ¿Cuál va a ser el papel del Trabajo Social en al erradicación de estos males que azotan a la humanidad? ¿Seguirá apoyándose en otras disciplinas que sirven al status quo o tratará de desarrollar su propia teoría y sus propios métodos forjándolos a golpe de experiencias, en sintonía con el pulso del pueblo? (Rivera, 1986, p. 206)

En su escrito La Enfermedad Social del Coloniaje, nos aclara:

No pretendo concluir que la causa de todos nuestros males sociales radique exclusivamente en la colonia. Pero si aseguro con plena conciencia del alcance de mi afirmación, que la colonia es un obstáculo perenne, constante y paralizador en el camino de nuestro progreso económicosocial y de nuestro crecimiento espiritual como pueblo... Treinta y cuatro años de experiencia en el trabajo social profesional han confirmado día a día mi firme convicción de que tampoco se puede ejercer eficazmente el trabajo social en un pueblo privado del elemental derecho a gobernarse a 
si mismo (Rivera, 1986, p. 32).

Y en su última aportación escrita al trabajo social, excelentemente, presentada trajo el título El Trabajo Social: Una Profesión en la Encrucijada; en el Primer Congreso Venezolano en el mes de junio de 1973, al que asistió como invitada especial; nos invita a la reflexión-acción, cuando señala:

La profesión de trabajo social está en uno de esos momentos culminantes en que tiene necesariamente que definir su posición en la sociedad. ¿Continuará atada a su tradición conservadorcita o estará dispuesta a sumir posiciones radicales frente a los problemas que afligen a las sociedades modernas? ¿Mantendrá su posición elitista de clase media o estará en disposición de vivir en la práctica lo que enseña en la teoría: la esencia igualdad del ser humano?

¿Se mantendrá como institución, aislada, desconectada del pueblo o se unirá a otros grupos de avanzada como una fuerza revolucionarla en solidaridad con las clases oprimidas? ¿Estará dispuesta a comprometerse? (Rivera, 1986, p. 158)

Han pasado cerca de cuarenta años del momento en que Doña Carmen, con autoridad indiscutible, nos convocó a unirnos a sectores de nuestro pueblo orientados a trabajar por las transformaciones estructurales que necesita urgentemente este terruño amado. Sus mensajes y retos cobran mayor pertinencia en el Puerto Rico del Siglo XXI. Estamos viviendo una de las peores, sino la peor crisis de nuestra historia. No es el momento para hacer un inventario de los indicadores de dicha crisis, que es multidimensional (económica, política, social, cultural, moral). Somos partícipes de ella. Nos azota diariamente y violentamente. Debemos rechazar, de entrada, el mensaje de que esta crisis es mundial y por lo tanto, poco podemos hacer. Este mensaje con dicha respuesta nos incapacita para comprender nuestra realidad nacional y disponernos a ser sujetos en los procesos que han de propiciar los cambios radicales que requiere nuestro ordenamiento social.

Yo estoy convencida de que para poder responder a las enseñanzas que hemos recibido, con gran respeto, de nuestra Maestra; es imprescindible aceptar plenamente la responsabilidad por el desarrollo de una conciencia crítica; por el análisis critico de nuestra práctica profesional; por el rescate del trabajo social comunitario y por la incursión en la política social, más allá de la prestación de servicios sociales. Los llamé retos en un escrito anterior a éste. Hoy, solicito vuestra generosidad para repasarlos, por entender que son acordes con la visión que tenía Doña Carmen, del trabajo social.

La conciencia crítica, que incluye el pensamiento crítico, usualmente no la desarrollamos a través de la educación formal que es fundamentalmente acrítica. Este señalamiento aplica a la educación en trabajo social. Para superar la conciencia mágica, la fanática, la dogmática o la ingenua y llegar a la crítica debe haber una voluntad genuina de entrar en procesos de reflexión-acción, que nos han de confrontar con el nivel de conciencia en que nos encontramos e iniciar el camino hacia el pensamiento y la conciencia crítica. Estos procesos de reflexión-acción deben darse en el trabajo colectivo, primordialmente, por entenderse que tiene mayor potencial que los que se dan en el anonimato, a solas; sin descartar el encuentro con nosotros(as) mismo(as) con miras al desarrollo ideológico. La compañera Magda Orfila Barreto, estudiosa del desarrollo del pensamiento y la conciencia crítica, aporta en uno de sus escritos, una definición de conciencia crítica, que es el nivel de desarrollo al que debemos aspirar los(as) trabajadores(as) sociales. Nos dice ella:

Conciencia crítica es el grado de conocimiento y de interpretación de la realidad que se construye, se alcanza o se desarrolla progresivamente o personalmente mediante la reflexión-acción en torno a la realidad objetiva y concreta en que se interactúa. Posibilita la integración de la persona al contexto socio cultural para promover el cambio y la transformación social a distintos grados de intensidad, 
profundidad y participación. Los procesos de desarrollo de la conciencia crítica son inconclusos. Una situación de inmersión te sigue llevando a otra sucesivamente. Esta demanda de los educadores educandos procesos de reflexión-acción más desarrollados y cada vez de mayor compromiso, de responsabilidad, de apertura de nuevos espacios y de constante búsqueda de probabilidades... Requiere por consiguiente, de un proceso continuo de superación y búsqueda para trascender la ingenuidad y las manifestaciones transitorias o inmediatas de la realidad contextual. Implica lo siguiente: interpretación y lectura crítica de la realidad; reflexión y problematización de la realidad a partir de la práctica e integración al proceso de acción socio cultural para el cambio. En resumen, conlleva reciprocidad entre el diálogo crítico y el desarrollo de la conciencia, la transformación personal, colectiva y sociocultural. (Orfila, 2007)

Visualizo al Colegio de Trabajadores Sociales, a través del Instituto de Educación Continua, trabajando con los(as) colegiados(as) vivencias que conduzcan al desarrollo del pensamiento y la conciencia crítica. Doña Carmen se adelantó a nuestro tiempo dándonos ejemplo de la capacidad para dicho desarrollo.

En ese pensamiento y conciencia crítica, la que nos ha de facilitar el analizar objetivamente nuestra realidad social y si también el ejercer responsablemente la auto-crítica de nuestra ejecutoria profesional.

Es un hecho comprobado que el trabajo social que aprendimos y que practicamos, ha estado dirigido mayormente al alivio, al control, a la adaptación, a la reforma, no así a la transformación estructural. Concuerdo con Gil (1998, p. 85), en que:

A pesar de que los trabajadores sociales y sus organizaciones y sus organizaciones tienden a repudiar la injusticia y la opresión, usualmente no retan a las fuentes sistémicas de la dinámica capitalista. Más aún, en la práctica actual, a pesar de sus valores y ética, los trabajadores sociales típicamente no se involucran en esfuerzos para confrontar y trascender la injusticia y la opresión y sus raíces en el tejido social. Estos tienden a considerar su práctica como políticamente neutral, y la separan por consiguiente de su rechazo filosófico a la injusticia y la opresión.

Este planteamiento de Gil, se fortalece con los hallazgos de una de las investigaciones de la compañera Dagmar Guardiola Ortiz (1998) y su equipo, sobre el Trabajo Social en Puerto Rico.

El estudio reveló que existe una contradicción entre el tipo de trabajo social que han practicado las trabajadoras sociales... que fue asistencialista (62.6\%) y el elemento que más ha estado relacionado a su práctica, que fue la transformación $(38.7 \%)$... Se concluye que la práctica del trabajo social es contradictoria ya que promueve tanto la transformación como la adaptación social por estar enmarcada en el contexto institucional estatal. Este responde al modelo de desarrollo económico dependiente cuyas políticas son asistencialistas, mientras que la profesión postula la transformación como fin último (p.65).

Resolver esta falta de correspondencia entre el discurso de la transformación y la práctica asistencialista constituye uno de los mayores retos para los(as) trabajadores(as) sociales. Doña Carmen nos ayuda a tomar la ruta hacia la transformación. En ella no había contradicción entre su discurso y su práctica. Mujer de una sola pieza...

El trabajo social profesional comienza en nuestro País a fines de la década de los 1920, con un enfoque comunitario, utilizando como metodología la educación popular. Un Puerto Rico, eminentemente rural, arropado por la pobreza y las epidemias, recibe Fondos Federales para implantar programas del Nuevo Trato. Se reclutan a trabajadoras(es) sociales que se entregaban en cuerpo y alma a 
las comunidades rurales para ocupar posiciones administrativas burocráticas. Ese fue el primer gran golpe al desarrollo de un trabajo social autóctono junto a las comunidades rurales empobrecidas. Se reforzó el asistencialismo para el alivio, el control y la adaptación social. Al introducirse en Puerto Rico un modelo de desarrollo económico dependiente, la práctica del trabajo social se convierte en un residual, o sea, habla que trabajar con los residuos sociales de ese modelo de desarrollo. Ese trabajo residual fue impactado por teorías, modelos, perspectivas, enfoques; producto de la sicología clínica y la siquiatría, a través de literatura que nos llegaba desde la metrópolis, en la cual se categorizan como disfunciones o patologías individuales, un gran número de problemas sociales. Por ser entes colonizados, aceptamos indiscriminadamente, lo que nos llega del Norte. El trabajo social se convierte en uno eminentemente remediativo, de tratamiento o terapéutico. En este proceso se asesta otro gran golpe al trabajo social comunitario, que ha sobrevivido más bien en el ámbito académico, no así en la práctica profesional que se lleva a cabo, mayormente, dentro de la estructura gubernamental.

Cuando los problemas sociales tienen su raíz en las estructuras económicas, políticas y sociales, y la prioridad del trabajo social debe ser la transformación social, se hace urgente el trabajo comunitario. Son los ciudadanos de nuestras comunidades que viven en carne propia la exclusión, la opresión el discrimen y la violencia institucional, los llamados a ser los actores y actrices principales en las luchas por las transformaciones estructurales que requiere nuestro país. Y en esas luchas tienen un espacio el(la) trabajador(a) social por su compromiso ético, sus conocimientos y destrezas.

La teoría y la práctica del trabajo social en Puerto Rico no se ha escapado del dominio colonial. Se añade a la importación indiscriminada de literatura desde la metrópolis, la ubicación que ese le ha asignado al trabajo social en los niveles en que se trabaja con la política social. Guardiola (1998, p. 45), nos recuerda que el marco inmediato en que se inserta el trabajo social en el proceso de reproducción de la sociedad capitalista es en el sistema de las políticas sociales. Amplia y refuerza su planteamiento al citar a Fernández y Rosas (1992) en que las políticas sociales son uno de los medios idóneos para corregir las desigualdades sociales generadas por la libre concurrencia que opera en el mercado capitalista. En ese sistema de las políticas sociales, encontramos en una proporción desmedida, a los(as) trabajadores(as) sociales, en el último nivel de dicho sistema. O sea, en la prestación de los servicios sociales que han de recibir las personas afectadas o vulnerables al problema del que se trate. En términos generales, no se le reconoce competencia a este profesional para definir el problema, ni para la selección de la(s) política(s) social(es) para enfrentar dicho problema, ni para el diseño de los programas a través de los cuales se ha de implantar y evaluar dicha(s) política(s)

Dada la subordinación política de nuestro país y la dependencia en Fondos Federales, una gran cantidad de las políticas programas y servicios sociales son de diseño extranjero. Por otro lado, hemos internalizado que las decisiones sobre la política social le corresponden primariamente a los cuerpos legislativos, como representantes del pueblo. El trabajo social transformador necesita de la democracia participativa, en que los sectores populares sean los actores y actrices principales en todas las etapas del proceso de la política social.

En dicho proceso se visualiza al trabajador(a) social como un(a) facilitador(a) mediante la educación liberadora, que promueve la conciencia crítica, la organización y la movilización de los sectores con quienes se trabaja. Este trabajo social puede parecer más político que profesional ante los ojos de compañeros(as) de profesión y personas ajenas a nuestra práctica. Cuando nuestra función profesional está orientada al alivio, al control a la adaptación o a la reforma, estamos haciendo trabajo político. La diferencia es clara. Al trabajar para la transformación estructural, lo hacemos con las fortalezas y el poder que tiene nuestra gente para alcanzar niveles de bienestar social que demuestren que el respeto a la dignidad humana trasciende el discurso y se torna en realidad viviente. Al trabajar para el alivio, el control y la adaptación, perpetuamos la dependencia que impide el más pleno desarrollo de nuestro pueblo.

VOCES DESDE EL TRABAJO SOCIAL

NÚM.1 
La incursión en las diferentes etapas de la política social, está íntimamente vinculada al trabajo social comunitario. Es esperanzador observar desarrollos académicos encaminados a sumir nuestra responsabilidad profesional en ambos contextos. El Instituto Universitario para el Desarrollo de las Comunidades en el Recinto de amigues de la Universidad de Puerto Rico y el Instituto de Política social creado bajo el Programa Doctoral en Investigación con Énfasis en Análisis y Administración de Política Social, en la Escuela Graduada de Trabajo Social, de la Universidad de Puerto Rico, Recinto de Rio Piedras; son desarrollos de avanzada que debemos apoyar. Es urgente su integración a la práctica cotidiana dentro y fuera de las estructuras gubernamentales y a la educación continua que ofrece el Colegio de Trabajadores Sociales. Para trabajar en el desarrollo de nuestro pensamiento y conciencia crítica, en el análisis crítico de nuestra práctica profesional, en un trabajo comunitario transformador y para ser entes proactivos en la política social; debemos nutrirnos del legado de Doña Carmen. Legado, que es un regalo de amor al pueblo puertorriqueño, y mas directamente a los(as) trabajadores(as) sociales. De mis lecturas sobre Doña Carmen, he querido seleccionar unas palabras, a modo de recapitulación, pronunciadas en el Ateneo Puertorriqueño, por el insigne académico y patriota don José Ferrer Canales; y que describen cabalmente a esa gran trabajadora social.

Ella encarnaba nobles ideales de humanitarismo: los de la paz fecunda, creadora y revolucionaria; los de la solidaridad social; la conciencia de que en la libertad de cada uno va la libertad de todos; la concepción ética y política que nos obliga a rechazar la esclavitud, el discrimen, el coloniaje; la que nos lanza a lidiar contra la tiranía, la injusticia y el imperialismo con todos sus acólicos o monaguillos.

...Mujer extraordinaria es ésta de Vega Baja, que vemos en la tradición que simboliza Lola Rodríguez de Tió, pero con un acento más en lo social, colectivo, que en lo lírico, subjetivo. Funde valores del mejor humanismo en la unidad de su alma, Y es entonces lo que tan bien define a Doña Carmen; ¡una verdadera voluntad insobornable! (Rivera, 1986, p. 200-201).

Gracias, Doña Carmen, por su legado. Quiero pensar que los(as) trabajadores(as) sociales en Puerto Rico, hemos comenzado a entender y aceptar que el trabajo social es ante todo, vocación de libertad. 


\section{Referencias}

Colón, Noel (2009). La Disidencia como Vocación. Rio Piedras,Puerto Rico. Publicaciones Gaviota.

Fernández, Arturo \& Rozas, Margarita (1992). Políticas Sociales y el Trabajo Social. Buenos Aires, Argentina. Editorial Humanitas.

Ferrer, José (1986). Carmen Rivera Alvarado: Insobornable. Lucha y Visión de Puerto Rico Libre. Rio Piedras, Puerto Rico. Fundación Alvarado Rivera.

Gil, David (1998). Conforting Injustice and Oppression: Concepts and Strategies for Social Workers. NewYork. Columbia University Press.

Guardiola, Dagmar (1998). El Trabajo Social en Puerto Rico: Asistencia, Desarrollo, Transformación? Rio Piedras, Puerto Rico. Editorial Edil.

Mari, Juan (1986). Prologo. Carmen Rivera Alvarado: Lucha y Visión de Puerto Rico Libre, Rio Piedras. Fundación Alvarado Rivera.

Martínez, Mercedes (1986). Recuerdo de una Admirable Trabajadora Social, Carmen Rivera Alvarado: Lucha y Visión de Puerto Rico Libre. Rio Piedras, Puerto Rico. Fundación Alvarado Rivera.

Orfila, Magda (2007). Diálogo Crítico y Desarrollo Humano Liberador. Aruba. Universidad de Aruba.

Rivera, Carmen (1986). Florida Toda Yo, Carmen Rivera Alvarado: Lucha y Visión de Puerto Rico Libre. Rio Piedras, Puerto Rico. Fundación Alvarado Rivera.
Rivera, Carmen (1986). Por que no asistí a Entrega de Honores, Carmen Rivera Alvarado: Lucha y Visión de Puerto Rico Libre. Rio Piedras, Puerto Rico, Fundación Alvarado Rivera.

Rivera, Carmen (1986) Visión del Trabajo Social en la República de Puerto Rico, Carmen Rivera Alvarado: Lucha y Visión de Puerto Rico Libre. Rio Piedras, Puerto Rico. Fundación Alvarado Rivera.

Rivera, Carmen (1986). La Enfermedad Social del Coloniaje, Carmen Rivera Alvarado: Lucha y Visión de Puerto Rico Libre. Rio Piedras, Puerto Rico. Fundación Alvarado Rivera.

Rivera, Carmen (1986). Trabajo Social: Vocación de Libertad. Carmen Rivera Alvarado: Lucha y Visión de Puerto Rico Libre. Rio Piedras, Puerto Rico. Fundación Alvarado Rivera.

Rivera, Carmen (1986). El Trabajo Social: Una Profesión en la Encrucijada, Carmen Rivera Alvarado: Lucha y Visión de Puerto Rico Libre. Rio Piedras, Puerto Rico. Fundación Alvarado Rivera. 